\title{
Efficacy of Transcutaneous Electrical Nerve Stimulation (TENS) in the Treatment of Bell's Palsy
}

Amina Shrestha, MD

Medicare National Hospital

Kathmandu, Nepal

Mohan R. Sharma, MS

Medicare National Hospital

Kathmandu, Nepal

Address for Correspondence:

Amina Shrestha, MD

Medicare National Hospital

Chahabil, Kathmandu, Nepal

Email: amina.shrestha@yahoo.com

Received, December, 2011

Accepted, December, 2011

$\mathrm{B}$ ell's palsy is a form of acute unilateral peripheral neuropathy of facial nerve. Facial nerve paralysis may have a number of etiologies. Most frequently it is idiopathic, that accounts for approximately half of all cases. Other common causes are Herpes Zoster Oticus, accidental or iatrogenic trauma and neoplasms. ${ }^{7}$ Whatever the cause, this condition can be devastating to the patient's psychology and social life. Facial nerve paralysis induces facial asymmetry leading to the loss of balanced appearance and function. Therefore, physicians treating this condition are most frequently asked "How much improvement can occur?" and "How long does it take to improve? Even though most patients with Bell's palsy recover completely spontaneously, a small number of individual also require active treatment..$^{3-5}$ Treatment modalities of Bell's palsy include antiviral agents, prednisolone, methylcobalamin, Hyperbaric Oxygen, facial retraining, Botulinum toxin for Synkinesis and hemifacial spasm and Transcutaneous Electrical Stimulation. ${ }^{-3,6,9,13}$ TENS is a non-invasive, drug free method of treatment. It is a portable battery powered stimulator and if used early is an acceptable tool for recovery.

The purpose of this study was to assess the clinical efficacy of TENS treatment in acute Bell's palsy.

\section{Materials and Methods}

One hundred and thirty two patients with Bell's palsy were retrospectively evaluated attending neurology outpatient clinic of Medicare National Hospital from June
Patient's with acute Bell's palsy were evaluated retrospectively for the efficacy of TENS treatment. One hundred and thirty two patients were divided into two groups. First group received only steroids, the second received steroids and TENS in combination. Patients were evaluated before and after treatment using compound muscle action potential derived from nerve conduction test (NCT) and House Brackmann Clinical Scale.

The clinical recovery in the second group was better and faster. It is concluded that TENS treatment in combination with steroids has better therapeutic effect than steroids alone in acute Bell's palsy.

Key words: bell's palsy, transcutaneous electrical nerve stimulation (TENS)

2004 to November 2011. After detail clinical evaluation and relevant radiological investigation a diagnosis of Bell's palsy was made. The patients were divided into two groups. Group A received corticosteroid prednisolone in a dose of $1 \mathrm{mg} / \mathrm{kg}$ for five days then the dose was tapered according to the recovery status. Group B received prednisolone plus TENS treatment. Patients who were unable to attend hospital daily for TENS treatment were included in Group A and the rest were included in Group B. Those who had contraindications for steroids or TENS and who came for treatment after more than 30 days of disease onset were excluded from the study. For those who received corticosteroids plus TENS treatment stimulation of the affected face area was done by TENS apparatus OMRON, model HV-F-127 (Japan) with two surface pads of size six $\mathrm{cm}$. Surface pads were placed over the most affected muscles. Stimulation intensity was tailored according to the tolerance for 15-30 minutes. Stimulation was done daily until improvement was seen for a maximum 30 days. There were 62 patients in Group A and 70 patients in Group B.

All the patients were evaluated before and after treatment using House Brackmann Clinical Scale and Compound Muscle Action Potential (CMAP) derived from NCT. ${ }^{8}$ House Brackmann Grading System has six grades of dysfunction.

Grade I- Normal

Grade II- Mild dysfunction

Grade III- Moderate dysfunction

Grade IV- Moderately severe dysfunction 


\section{Shrestha et al.}

Grade V-Severe dysfunction

Grade VI-Total paralysis

Facial Paralysis severity grading based on CMAP is as follows:

Mild - CMAP amplitude more than $30 \%$ compared to the healthy side

Mod - CMAP amplitude 10-30\% compared to the healthy side

Severe - CMAP amplitude less than $10 \%$ compared to the healthy side

\section{Results}

The age of the studied patients ranged from 2 to 81 years (Table 1). Out of 132 patients there were 63 males and 69 females ( Table 2 ). Seventy four patients presented for treatment before seven days of disease onset and 58 patients presented at 7-30 days of disease onset (Table 3).

Before treatment patients were evaluated based on CMAP. Twenty-five patients had Mild, 85 patients had moderate and 22 patients had severe neurological impairment. On House Brackmann Grading Scale, 20 patients had Grade II, 22 patients had Grade III, 50 patients had Grade IV, 40 patients had Grade V and none had Grade VI dysfunction ( Table 4 ).

Patients on Steroids and TENS (Group-B) recovered better and faster than patients only on Steroids (Group A). Patients who came for treatment earlier i.e. before 7 days of disease onset recovered in less than 2-3 weeks. Those who came later at 7 to 30 days of disease onset took more time to recover.

Patients on steroids (Group A) also recovered but took a longer period (2-6 months). The House Brackmann Grading Scale exhibited improvement in all patients. In Group A an improvement by Grade I-II was observed in 15 patients $(25 \%)$, Grade II-IV in 35 patients $(58.3 \%)$, Grade IV-VI in 10 patients $(16.7 \%)$. In Group B an improvement by Grade I-II was observed in 0 patients, Grade II-IV in 47 patients $(65.3 \%)$, Grade IV-VI in 25 patients $(34.7 \%)$.
Nerve conduction studies also revealed improvement in CMAP. In Group A there was increase in CMAP of $<10 \%$ in 10 patients $(16.7 \%), 10-30 \%$ in 35 patients $(58.3$ $\%$ ), and $>30 \%$ in 15 patients ( $25 \%$ ). In Group B there was increase in CMAP of $10-30 \%$ in 48 patients $(66.7 \%)$, $>30 \%$ in 24 patients $(33.5 \%)$ (Table 5).

\begin{tabular}{|l|l|l|}
\hline Age Group(Years) & No of Patients & \% \\
\hline $0-15$ & 10 & 7.6 \\
\hline $16-50$ & 85 & 64.4 \\
\hline Above 50 & 37 & 28 \\
\hline
\end{tabular}

Table 1: Distribution of Patients by Age Group

\begin{tabular}{|l|l|l|}
\hline Gender & No of Patients & \% \\
\hline Male & 63 & 47.7 \\
\hline Female & 69 & 52.3 \\
\hline Total & 132 & 100 \\
\hline
\end{tabular}

Table 2: Distribution of Patients by Sex

\begin{tabular}{|l|l|l|}
\hline & No of Patients & \% \\
\hline Before 7 days & 74 & 56.1 \\
\hline 7-30 days & 58 & 43.9 \\
\hline Total & 132 & 100.0 \\
\hline
\end{tabular}

Table 3: Distribution of Patients by Time of Presentation

\begin{tabular}{|l|l|l|l|}
\hline CMAP & No. of Patients & HB Scale & No. of Patients \\
\hline Mild & $25(18.9 \%)$ & Grade-I & $20(15.2 \%)$ \\
\hline Mod & $85(64.4 \%)$ & Grade-II & $22(16.7 \%)$ \\
\hline Sev. & $22(16.7 \%)$ & Grade-IV & $50(37.9 \%)$ \\
\hline & & Grade-V & $40(30.3 \%)$ \\
\hline & & Grade-VI & \\
\hline Total & $132(100 \%)$ & Total & $132(100 \%)$ \\
\hline
\end{tabular}

Table 4: Evaluation of Patients before treatment

\begin{tabular}{|l|l|l|l|l|l|}
\hline \multicolumn{2}{|c|}{ Recovery Status } \\
\hline Based on CMAP & \multicolumn{2}{|c|}{ No. of Patients } & \multicolumn{2}{l|}{ Based on HB Scale } & \multicolumn{2}{l|}{ No. of Patients } \\
\hline & Group A & Group B & & \multicolumn{1}{|c|}{ Group A } & Group B \\
\hline $\begin{array}{l}\text { Satisfactory } \\
(<10 \% \text { increase })\end{array}$ & $10(16.7 \%)$ & 0 & $\begin{array}{l}\text { Satisfactory } \\
\text { Improvement by Grade I-II) }\end{array}$ & $15(25 \%)$ & 0 \\
\hline $\begin{array}{l}\text { Good } \\
(10-30 \% \text { increase })\end{array}$ & $35(58.3 \%)$ & $48(66.7 \%)$ & $\begin{array}{l}\text { Good } \\
(\text { improvement by Grade II-IV) }\end{array}$ & $35(58.3 \%)$ & $47(65.3 \%)$ \\
\hline $\begin{array}{l}\text { Excellent } \\
(>30 \% \text { increase })\end{array}$ & $15(25 \%)$ & $24(33.3 \%)$ & $\begin{array}{l}\text { Excellent } \\
\text { (Improvement by Grade IV-VI) }\end{array}$ & $10(16.7 \%)$ & $25(34.7 \%)$ \\
\hline Total & $60(100 \%)$ & $72(100 \%)$ & Total & $60(100 \%)$ & $72(100 \%)$ \\
\hline
\end{tabular}

Table 5: Evaluation of Patients after treatment 
There was no difference in the outcome between males and females, and between different age groups. No complications directly referable to treatment modalities were encountered.

\section{Discussion}

Although in most patients idiopathic facial paralysis improves spontaneously some cases do suffer residual deficits. The standard clinical practice is unlikely to offer them effective treatment after chronic state has become established. The present series explores possible avenue administered treatment that seems to be free of adverse effects and seems to be well tolerated by the patients.

In the present study, the House Brackmann Scale indicated that improvement took place in less than two weeks for those who appeared before seven days of the disease onset. Recent reviews concluded that Bell's palsy could be effectively treated with corticosteroids in the first seven days, providing up to a further $17 \%$ of the patients with good outcome in addition to the $80 \%$ spontaneous improvement. ${ }^{4,1012,14}$ As all patients are eager for speedy recovery, we would like to give them chance that no one would like to have residual effects. In this study those with steroids and TENS recovered earlier while those with steroids alone took more time.

\section{Conclusion}

TENS treatment in combination with Steroids has a better therapeutic effect than steroids alone in the treatment of acute Bell's palsy. Those who present early for treatment have faster and better outcome.

\section{References}

1. Diels HJ, Combs D: Neuromuscular retraining for facial paralysis. Otolaryngol Clin North Am 30:727743, 1997

2. Diels HJ: Facial paralysis: Is there a role for therapist? Facial Plast Surg 16: 361-364, 2000
3. Farragher D, Kidd GL, Tallis R: Eutrophic electrical stimulation for Bell's palsy. Clin Rehabil 1: 265-271, 1987

4. Hato N, Matsumoto S: Efficacy of early treatment of Bell's palsy with oral acyclovir and prednisolone. Otol Neurotol 24: 948-951, 2003

5. Hato N, Yamaha H, Konho H, et al: Val acyclovir and prednisolone treatment for Bell's palsy: A multi-center, randomized, placebo-controlled study. Otol Neurotol 27: 408-413, 2007

6. Holland NJ, Graeme M Weiner: Recent development in Bell's palsy. BMJ 10: 1136, 2004

7. Marenda SA, Olsson JE: The evaluation of facial paralysis. Otolaryngol Clin North Am 30:669-82, 1997

8. Mishra UK, Kalita J: Bell's Palsy. Clinical neurophysiology 4: 83-84, 2004

9. Mosforth J, Taverner D: Physiotherapy for Bell's palsy. BMJ 46: 675-677, 1958

10. Ramsey M J, DerSimonian R, Holtel MR, Burgess LP: Corticosteroid treatment for idiopathic facial nerve paralysis: a meta - analysis. Laryngoscope 110: 335 341,2000

11. Segal B, Hunter T: Minimizing synkinesis during rehabilitation of the paralyzed face: Preliminary assessment of a new small-movement therapy. J Otolaryngol 24: 149-153, 1995

12. Shafshak TS, Essa AY, Bakey FA: The possible contributing factors for the success of steroids therapy in Bell's palsy: a clinical and electrophysiological study. J Laryngol Otol 108: 940-943, 1994

13. Targan RS, Alon G, Kay SL: Effect of long term electrical stimulation on motor recovery and improvement on clinical residual in effects patients with un-resolved facial nerve palsy. Otolaryngol Head Neck Surg 122: 246-252, 2000

14. Williamson IG, Whelan TR: The clinical problem of Bell's palsy: is treatment with steroids effective? $\mathbf{B r}$ J Gen Pract 46: 743-747, 1996

15. Yanagihara N, Hato, Murakami S, et al: Tran mastoid decompression as a treatment of Bell's palsy. Otolaryngol Head Neck Surg 124: 282-286, 2001 